\title{
TÁC PHẨM HỒI KÝ KHÔNG CÓ THẢN THOAI \\ CỦA LEE MYUNG BAK VÀ NHŨ̉NG CHIỀU KÍCH HOFSTEDE TRONG VĂN HÓA DOANH NGHIỆP HÀN QUỐC
}

\author{
Phan Thị Thu Hiền* \\ Truoòng Đại học Khoa học Xã hội và Nhân văn, Đại học Quốc gia Thành phố Hồ Chí Mính, \\ 10-12 Đinh Tiên Hoàng, Phuờng Bến Nghé, Quận 1, Tp. Hồ Chí Minh, Việt Nam \\ Nhận bài ngày 28 tháng 09 năm 2017 \\ Chỉnh sửa ngày 19 tháng 01 năm 2018; Chấp nhận đăng ngày 22 tháng 01 năm 2018
}

Tóm tắt: Hồi ký Không có thần thoại của cựu Tổng thống Lee Myung Bak, cựu Chủ tịch tập đoàn Hyundai có thể xem là một trường hợp đại diện và điển hình cho truyện ký về cuộc đời những "người hùng" của các tập đoàn Hàn Quốc. Qua một nhân vật xuất chúng mà số phận gắn bó với sự hình thành, phát triển một trong những tập đoàn hàng đầu của Hàn Quốc, Không có thần thoại giúp chúng ta cảm hiểu nguồn sức mạnh đã làm nên "kỳ tích sông Hàn", tính cách con người và bản sắc dân tộc Hàn nói chung; đặc điểm văn hóa doanh nhân, văn hóa doanh nghiệp Hàn Quốc nói riêng. Bài nghiên cứu này vận dụng các chiều kích Geert Hofstede để tiếp cận liên ngành tìm hiểu văn hóa doanh nghiệp Hàn Quốc dựa trên dữ liệu văn học truyện ký doanh nhân.

Tù khóa: văn học đại chúng Hàn Quốc, văn hóa doanh nghiệp Hàn Quốc, những chiều kích văn hóa Hofstede, tập đoàn Hyundai, hồi ký Không có thần thoại của Lee Myung Bak

\section{Hồi ký Không có thần thoại của Lee} Myung Bak và hướng tiếp cận từ các chiều

\section{kích Hofstede}

1.1. Hồi ký Không có thần thoại của Lee Myung Bak với tu cách một trương hợp điển hìh của truyện ký doanh nhân

Hồi ký Không có thần thoại của Lee Myung Bak kể về cuộc đời ông - sinh ra và lớn lên trong nghèo khó, trở thành Tổng giám đốc công ty Hyundai những năm 30 tuổi, Chủ tịch tập đoàn những năm 40 tuổi, Thị trưởng thành phố Seoul những năm 50 tuổi, Tổng thống Đại Hàn Dân Quốc những năm 60 tuổi. Cuộc đời ấy thường được xem như một huyền thoại vĩ đại. Tuy nhiên, theo Lee Myung Bak, không có phép màu kỳ diệu, thần tiên nào cả, "chi có ý chí nóng bỏng của một con người dám dấn thân, biết đột phá bao nguy cơ và thư

\footnotetext{
* ĐT.: 84-918349348

Email: phanthithuhien@hcmussh.edu.vn
}

thách trong ngoài”. Quá trình trưởng thành của cá nhân Lee Myung Bak gắn bó chặt chẽ cùng những bước tiến của Hyundai, từ doanh nghiệp vô danh thành tập đoàn lớn có tiếng tăm quốc tế, gắn bó chặt chẽ cùng tăng trưởng thần kỳ của Hàn Quốc, thu nhập bình quân đầu người từ 80 USD cuối những năm 50 nhảy vọt lên 10.000 USD vào năm 1992 .

Không có thần thoại có thể xem là một trường hợp đại diện và điển hình của các "Truyện ký doanh nhân" / "Truyện ký doanh nghiệp" (기업 / 경영자 스토리) đặc biệt nở rộ trong văn học đại chúng (popular culture) Hàn Quốc. Bao gồm hồi ký, tự truyện và cả một số truyện ký, tiểu thuyết (dựa trên cuộc đời thật của nguyên mẫu) về các vị chủ tịch, tổng giám đốc... của các tập đoàn lớn của Hàn Quốc, thể loại tự sự này nằm ở khu vực giao giữa sách văn học và sách kinh tế, kinh doanh (경제/경영), sách phát triển năng lực lãnh đạo (리더십 개발), phát triển bản thân. 
Nhiều tác phẩm truyện ký doanh nhân đã trở thành các hiện tượng best-seller nổi bật nhất. Chẳng hạn, tự truyện Thế giới quả là rộng lớn và có rất nhiều việc phải làm của Kim Woo Choong trở thành cuốn sách bán chạy nhất thế giới được ghi vào kỷ lục Guinness năm 1989: chỉ trong vòng 4 tháng được tái bản 74 lần và được bán ra ở Hàn Quốc 20.000 bản ngay trong 3 ngày đầu tiên, hơn 1 triệu bản trong hơn 5 tháng, hơn 1,67 triệu bản trong vòng một năm (dân số Hàn Quốc lúc đó chỉ là 42 triệu). Riêng Không có thần thoại của Lee Myung Bak xuất bản lần đầu năm 1995, tính đến năm 2007, đã được tái bản đến 117 lần.

Nhiều truyện ký doanh nhân nổi bật được dịch và xuất bản ở nước ngoài, cũng góp phần đem những giá trị Hàn Quốc tới châu Á và các châu lục khác. Thế giới quả là rộng lớn và có rất nhiều việc phải làm của Kim Woo Choong đã được dịch ra 17 thứ tiếng và xuất bản tại 23 quốc gia (Anh, Nhật, Trung Quốc, Nga, Tây Ban Nha, Ba Tư, Hungari, Mông Cổ, Malaysia, Italia, Việt Nam...). Ngườ đàn ông của thép được dịch ra tiếng Trung, tiếng Việt... Không có thần thoại của Lee Myung Bak được dịch ra tiếng Anh, tiếng Nhật, tiếng Kazakhxtan, tiếng Việt...

Những tác phẩm truyện ký doanh nhân Hàn Quốc tiêu biểu đã được dịch ra tiếng Việt, bao gồm:

- Tự truyện Thế giới quả là rộng lón và có rất nhiều việc phái làm của Kim Woo Choong, nhà sáng lập và cựu Chủ tịch tập đoàn Daewoo (Phan Thùy Chi dịch. NXB Đại học Kinh tế Quốc dân 2015)

- Tự truyện Không bao giờ là thất bại. Tất cả chi là thử thách của Chung Ju Yung (Người sáng lập và cố Chủ tịch tập đoàn Hyundai). (Lê Huy Khoa dịch. NXB Trẻ 2015).

- Hồi ký Không có thần thoại của Lee Myung Bak, cựu Chủ tịch tập đoàn Hyundai, cựu Tổng thống Đại Hàn Dân Quốc.

- Truyện ký Người đàn ông của thép của Lee Dae Hwan (viết về ông Park Tae Joon, cựu Thủ tướng, cựu Chủ tịch tập đoàn Posco).
(Ku Su Jeong, Nguyễn Ngọc Tuyền dịch, Trần Quang Thi nhuận sắc. NXB Trẻ 2009).

- Tiểu thuyết Người anh hùng bị bỏ rơi của An Hy Sook (viết về ông Kim Woo Choong, cựu Chủ tịch tập đoàn Daewoo). (Vũ Hữu Trường dịch. NXB Văn hóa Thông tin 2006).

Không có thần thoại của Lee Myung Bak có đến ba phiên bản Việt ngữ. Trong bài viết này, chúng tôi sử dụng bản dịch của GS. Cho Jae Hyun, nguyên Trưởng khoa tiếng Việt của Trường Đại học Ngoại ngữ Hàn Quốc, được Hội Hữu nghị Hàn-Việt, Seoul xuất bản năm 2009.

Ở Hàn Quốc cũng như ở nước ngoài, đã có những nghiên cứu hồi ký của Lee Myung Bak. Chẳng hạn như bài "Tìm hiểu bản sắc người Hàn qua công trình đường cao tốc Hàn Quốc" của Parit Yinsen (Thái Lan) ${ }^{(1)}$, trong đó, tác giả đã phân tích Không có thần thoại để làm sáng rõ tính cách người Hàn.

Bài viết này của chúng tôi sẽ thử nghiệm đọc tác phẩm từ những chiều kích Hofstede.

\subsection{Geert Hofstede với nhüng chiều kich văn hóa doanh nghiệp}

Geert Hofstede (sinh năm 1928) là học giả nổi tiếng thế giới về những công trình nghiên cứu tâm lý học trong giao tiếp liên văn hóa, quản trị đa văn hóa. Những công trình của ông suốt từ những năm 1970 đến nay luôn luôn thu hút sự chú ý của giới học giả.

Theo Geert Hofstede, "Văn hóa là sụ" lập trình tu duy có tính tập thể, phân biệt nhũng thành viên của nhóm / cộng đồng này với nhũng thành viên của nhóm / cộng đồng khác”. Ông cũng định nghĩa văn hóa doanh nghiệp là một trong những "lớp văn hóa", thể hiện "cách thức mà nhà quản lý / nhân viên được xã hội hóa trong tổ chức lao động của ho" (2011: 3).

${ }^{1}$ Parit Yinsen (2014). Survey Korean Identities through
Korea Highway https://www.researchgate.net/publication/312300713 Survey_Korean_Identities_through_Korea_Highway' (truy cập 18/1/2018). 
G. Hofstede đã xác định 6 chiều kích giá trị có liên quan và ảnh hưởng đến văn hóa doanh nghiệp, đó là:

(1) "Khoảng cách quyền lực" (Power Distance)

(2) "Chủ nghĩa cá nhân" (Individualism) trong sự tương phản với "Chủ nghĩa cộng đồng" (Collectivism)

(3) "Nam tính" (Masculinity) trong sự tương phản với "Nữ tính" (Femininity)

(4) “Tránh sự bất định" (Uncertainty Avoidance)

(5) “Định hướng dài hạn" (Long-term Orientation) trong sự tương phản với "Định hướng ngắn hạn" (Short-term Orientation)

(6) “Thoải mái / Hưởng thụ” (Indulgence) trong sự tương phản với "Kiềm chế / Khắc kỷ" (Restraint).

Đóng góp của G. Hofstede không chỉ là kiến tạo khung lý thuyết bao gồm những chiều kích cơ bản quan trọng giúp nhận diện những giá trị văn hóa doanh nghiệp, văn hóa dân tộc mà còn qua khảo sát xã hội học thực hiện liên tục nhiều năm với quy mô, số lượng lớn trên mẫu có tính đại diện, tính điển hình cao, đưa ra được những chỉ số về các chiều kích ấy trong nhiều nền văn hóa khác nhau. Kết quả nghiên cứu cập nhật nhất hiện nay của G. Hofstede là kho dữ liệu về 101 nước, cung cấp một nguồn tư liệu tham khảo phong phú cho nghiên cứu so sánh các nước, các khu vực trên thế giới.

Liên quan đến văn hóa doanh nghiệp Hàn Quốc, nhiều công trình nghiên cứu ở Hàn Quốc và trên thế giới thường sử dụng hướng tiếp cận văn hóa so sánh, đặc biệt là so sánh Hàn Quốc với Hoa Kỳ. Sở dĩ như vậy vì một mặt, từ phương diện so sánh loại hình, đặc điểm văn hóa Hàn Quốc thuộc châu Á, Phương Đông hiện ra rõ nét trong so sánh với Hoa Kỳ thuộc Phương Tây. Mặt khác, Hoa Kỳ là nước quan trọng hàng đầu trong quan hệ chính trị - kinh tế - văn hóa giữa Hàn Quốc với phương Tây; Hoa Kỳ đến nay vẫn là đồng minh thân thiết của Hàn Quốc, liên quan đến những hợp tác sâu rộng về nhiều mặt giữa hai bên. Do đó, từ phương diện so sánh ảnh hưởng cũng có thể nhận thấy những biến đổi văn hóa Hàn Quốc từ truyền thống đến hiện đại do tiếp biến ảnh hưởng Âu Mỹ.

Trích ra để so sánh các chiều kích Hofstede trong văn hóa Hàn Quốc và văn hóa Hoa Kỳ theo kết quả nghiên cứu cập nhật nhất của Trung tâm Hofstede (truy cập Hofstede Insight 18/1/2018), ta thấy văn hóa doanh nghiệp Hàn Quốc (thuộc châu Á, phương Đông) và Hoa Kỳ (thuộc phương Tây) tương phản nhau một cách sắc nét về cả 6 chiều kích giá trị. Doanh nghiệp Hàn Quốc có Khoảng cách quyền lục cao trong khi doanh nghiệp Hoa Kỳ có Khoảng cách quyền lực thấp. Doanh nghiệp Hàn Quốc nổi bật Chủ nghĩa cộng đồng trong khi doanh nghiệp Hoa Kỳ nổi bật Chủ nghĩa cá nhân. Doanh nghiệp Hàn Quốc thiên về $N \tilde{u}$ tính trong khi doanh nghiệp Hoa Kỳ thiên về Nam tính. Mức độ Tránh sụ bất định trong doanh nghiệp Hàn Quốc rất cao, mức độ tránh bất định của doanh nghiệp Hoa Kỳ lại khá thấp. Doanh nghiệp Hàn Quốc có khuynh hướng Định huoóng dài hạn trong khi doanh nghiệp Hoa Kỳ có khuynh hướng Định hướng ngắn hạn. Doanh nghiệp Hàn Quốc thể hiện rõ tinh thần kiềm chế / khắc kỷ, doanh nghiệp Hoa Kỳ lại thể hiện tinh thần thoải mái, hưởng thụ. 


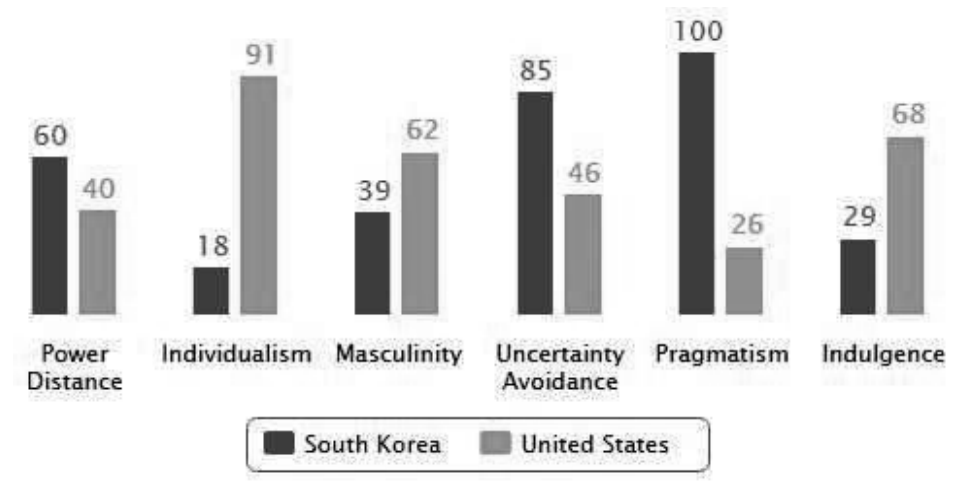

Hình 1. So sánh văn hóa doanh nghiệp Hàn Quốc và Hoa Kỳ theo các chiều kích Hofstede (Kết quả tù Trung tâm G.Hofstede) $^{(2)}$

Các chỉ số của Hofstede dựa trên khảo sát nhân viên người Hàn tại các công ty IBM ở Hàn Quốc, nghĩa là đối tượng quần chúng (mass) thuộc tầng đáy rộng (base) của doanh nghiệp. Với truyện ký về các chủ tịch tập đoàn, chúng ta có nguồn dữ liệu bổ sung để kiểm chứng các chỉ số này từ đối tượng tinh hoa (elite) thuộc đỉnh chóp (top) doanh nghiệp. Giả thuyết nghiên cứu của chúng tôi là hệ giá trị của các doanh nhân kiệt xuất như Lee Myung Bak có thể bao gồm cả những điểm xa chệch với mẫu số chung Hàn Quốc, có thể bao gồm sự khắc phục những hạn chế trong đặc tính truyền thống của một dân tộc Đông Á để tiệm cận với những ưu điểm của văn hóa doanh nghiệp hiện đại các nước Âu Mỹ.

\section{Hồi ký Không có thần thoại của Lee Myung Bak đọc từ những chiều kích Hofstede}

Trong hồi ký của mình, Lee Myung Bak không kể tuần tự theo trình tự thời gian. Câu chuyện bắt đầu khi ông 50 tuổi, suy nghĩ về "Lý do rời bỏ Hyundai" (tên chương 1). Từ đây, nhìn lại cuộc đời mình, ông đúc kết "Người thầy của tôi chính là mẹ tôi và sự nghèo khó" (tên chương 2). Các chương sách còn lại, mỗi chương tập trung vào một

\footnotetext{
2 Từ Hofstede Insights https://www.hofstede-insights. com/country-comparison/south-korea,the-usa/ (truy cập 18/1/2018)
}

chủ đề tư tưởng hơn là chỉ xâu chuỗi các sự kiện. Khá nhiều tên chương mục mang tính khơi gợi vấn đề (Chương 4: "Kẻ mạnh không bao giờ vòng vo", Chương 8: "Chủ tịch Lee cũng có gia đình chứ”, Chương 9: "Có một tương lai cho phương Bắc") hoặc dùng dạng thức mệnh lệnh nêu lên một xử thế (Chương 3: "Hãy nắm bắt công việc", Chương 5: "Hãy suy nghĩ như Tổng giám đốc và hãy chạy như Trưởng phòng”)... Trong mỗi chương lại có nhiều mục, tên của các mục, tất nhiên, phong phú, đa dạng hơn. Có khi căng thẳng kịch tính ("Một trận giữa giám đốc công trường thâm niên và một nhân viên trẻ mới”, "Con trai của Chủ tịch và Tổng giám đốc làm công ăn lương”...). Có khi tràn đầy xúc cảm ("Ôi, mẹ ơi"; "Ù, cứ khóc cho thoải mái"; "Những giọt nước mắt máu"...). Cũng không thiếu các sắc thái hài hước, hóm hỉnh ("Cái mông của Thủ tướng to hơn người khác sao?", "Lee Myung Bak sống với vợ 1ẽ”, “Thứ bảy cũng mặc đồ vest”...). Nổi bật trên tất cả, trong hồi ký của Lee Myung Bak là giọng chân thành trò chuyện, tâm tình, những lời khuyên nhủ cũng dễ dàng đi vào lòng người bởi trước hết chúng vốn là tự vấn, tự kiểm, tự dặn dò, khuyên nhủ chính mình.

Một điều thú vị là những trục chủ đề chính mà Lee Myung Bak đã gom các câu chuyện đời mình có rất nhiều tương ứng với sáu chiều kích văn hóa của Hofstede. 
2.1. Chủ nghĩa công đồng: Hết mình vì tập đoàn, tận hiến cho dân tộc

Theo Hofstede, Chủ nghĩa cá nhân và Chủ nghĩa cộng đồng liên quan "múc độ tương thuộc mà một xã hội duy trì giũa nhũng thành viên của nó". Nó liên quan đến hình ảnh tự ngã của người ta được nhận diện trong thuật ngữ "tôi”" hay "chúng ta".

"Chủ nghĩa cá nhân gắn với xã hội có it sự kết nối giữa các cá nhân với nhau: một người chỉ chăm sóc cho bản thân và gia đình trực tiếp của minh. Ngược lại, chủ nghĩa cộng đồng gắn với xã hội có nhũ̃ng cá nhân ngay tù̀ lúc sinh ra đã gắn bó trung thành với một tập thể mạnh mẽ, đoàn kết và suốt đời bảo vệ lợ ich của bản thân ho" (Geert Hofstede et al, 2013: 132).

Nghiên cứu của Hofstede cho thấy văn hóa doanh nghiệp Hàn Quốc thể hiện Chủ nghĩa cộng đồng cao, khác với Chủ nghĩa cá nhân thống lĩnh trong văn hóa doanh nghiệp Hoa Kỳ.

Nổi bật trong Không có thần thoại là hình ảnh Lee Myung Bak nỗ lực phấn đấu cho doanh nghiệp mà ông xem như gia đình, tận hiến phụng sự Tổ quốc mà ông xem như gia đình vĩ đại của mình. Ông gắn bó hoàn cảnh cha mẹ nghèo khó của mình với hoàn cảnh đất nước Hàn Quốc nhỏ hẹp, không có tài nguyên, bị chia cắt. "Tôi chăng trách móc bố mẹ, cũng chẳng có việc gì để oán hận đất nước nghèo nàn" (tr. 277). Để thoát ra khỏi cái nghèo như định mệnh, xây dựng đất nước thịnh vượng, Lee Myung Bak chỉ ngủ 4 tiếng hàng đêm, dốc sức cho công việc. Cháy bỏng trong Lee Myung Bak nhiệt huyết với sứ mệnh kinh doanh báo quốc.

Là công việc của doanh nghiệp nhung trong một quốc gia tu bản chủ nghĩa, doanh nghiệp là trọng tâm nên kết cục là công việc vì đất nuớc. Cá nhân tôi cũng truơong thành tù nghèo đói nên khắc phuc nghèo đói là bài toán của cá nhân tôi đồng thời là nhiệm vu mang tính quốc gia" (tr. 223).

Quan trọng nhất, với Lee Myung Bak, "phải sống sao thật xứng đáng là chủ nhân hơn là mang ý nghĩa ông chû" (tr.29). Chủ nhân của doanh nghiệp, chủ nhân của đất nước hành động quên mình cho doanh nghiệp, cho đất nước hơn là quan tâm đến quyền lực và hưởng thụ. Khi làm nhân viên kế toán văn phòng đại diện tại Thái Lan, Lee Myung Bak bị một bọn giang hồ lăm lăm mã tấu tấn công, buộc phải mở két sắt. Lee đã ôm chặt két sắt như "ôm chặt lòng tụ trọng của mình", đem mạng sống để bảo vệ tài sản của công ty (tr. 121). Sau hết một cuộc đời cống hiến, kiểm kê lại tài sản, Lee Myung Bak và phu nhân của ông quyết định "sẽ không nhường tài sản lại cho con cái" mà dùng tài sản đó thành lập một quỹ nghiên cứu tương lai của bán đảo Hàn và Đông Á.

Chủ nghĩa cộng đồng trong văn hóa truyền thống của người Hàn đặt tiêu cự trên chủ nghĩa gia tộc, coi trọng "mun trung” (môn trung), "Máu đặc hơn nước lã". Đi vào văn hóa doanh nghiệp, một trong những nguyên tắc quan trọng là nguyên tắc của hệ thống gia đình có xu hướng huyết thống (Principle of Blood-oriented Family System). Nhiều doanh nghiệp mang tính gia đình trị, huy động vốn và điều hành công việc bởi các thành viên trong gia đình, quyền lực theo lối cha truyền con nối. Theo Ủy ban Thương mại Bình đẳng Hàn Quốc, hình thức sở hữu của các gia đình trong 30 Chaebol (tập đoàn) lớn nhất Hàn Quốc tăng từ 43,8\% năm 1995 lên 44,1\% năm 1996, 44,5\% năm 1998 và năm 1999 tăng lên tới $50,5 \%$. Trong suốt mấy thập kỷ tồn tại, $90 \%$ quyền thừa kế tập đoàn được chuyển từ cha sang con trai hoặc anh em trai ${ }^{(3)}$.

Với Lee Myung Bak, Tổ quốc được xem là đại gia đình, ông đặt quyền lợi gia tộc dưới quyền lợi của Tổ quốc. Sự phân biệt giữa in-group (trong nhóm) và out-group (ngoài nhóm), theo ông, nên là giữa Hàn Quốc với các cường quốc trên thế giới mà nó phải cạnh tranh hơn là giữa các tập đoàn cùng của Hàn Quốc. Khi Hyundai và Samsung xung đột gay gắt trong vụ Trung ương Nhật báo, Lee

\footnotetext{
${ }^{3}$ Joseph E. Stiglitz \& Shahid Yusuf (2002).
} 
Myung Bak nỗ lực góp phần cho hòa giải hai tập đoàn lớn nhất Hàn Quốc "thoát khỏi mâu thuẫn tiêu hao", chuyển sang thời kỳ mới của những "cạnh tranh có thiện y" một cách tích cực, "là động lực nuôi duõng sức cạnh tranh không nhüng cho doanh nghiệp mà cho quốc gia nũa" (tr. 167). Khái niệm "Uri" (chúng ta) được Lee Myung Bak mở rộng vì sự sống còn, được mất của dân tộc hơn là của những tập đoàn hay những doanh nghiệp.

\subsection{Hiệu quả quản lý, quản trị nguồn nhân} lực thay cho chủ nghĩa quyền uy

\section{Theo Hofstede,}

"Khoảng cách quyền lực là mức độ mà nhũng thành viên it quyền lực của các tổ chức hoặc đon vị trong một quốc gia hy vong và chấp nhận sự bất bình đẳng trong phân chia quyền lucc" (Geert Hofstede et al, 2013: 95).

Nghiên cứu của Hofstede cho thấy văn hóa doanh nghiệp Hàn Quốc thể hiện khoảng cách quyền lực cao (tôn ti trật tự hơn), khác với khoảng cách quyền lực thấp (dân chủ, bình đẳng hơn) trong văn hóa doanh nghiệp Hoa Kỳ.

Khá nhiều công trình của các nhà nghiên cứu Hàn Quốc và nước ngoài nhất trí rằng văn hóa doanh nghiệp Hàn Quốc là sự mở rộng của văn hóa gia đình truyền thống theo lối gia trưởng, thể hiện qua người lãnh đạo trong vai trò người cha đứng đầu gia đình, cai trị bằng quyền lực tuyệt đối. Nổi bật là nguyên tắc tập trung quyền lực. Tục ngữ Hàn Quốc có câu: 상좌가많으면가마솥을깨드린다 (Nhiều thượng tọa thì vỡ cả nồi gang). Ngay cả ngày nay, khi một thế hệ nhà quản lý trẻ học hành từ phương Tây trở về, tiếp thu ảnh hưởng phương Tây, quản lý phân cấp (delegation of authority) và giải trung tâm quá trình ra quyết định (decentralized decision-making process) thì về cơ bản, quản trị doanh nghiệp Hàn Quốc vẫn mang tính uy quyền và gia trưởng (Chan Sup Chang \& Nahn Joo Chang, 1994: 135136). Trong quá trình ra quyết định của doanh nghiệp Hàn Quốc, được gọi là Pumui, việc lấy ý kiến cấp dưới phần nhiều chỉ để tham khảo, thậm chí chỉ mang tính hình thức, để chính thức hóa một quyết định do cấp trên tự quyết. Nguyên tắc trật cấp (Principle of Strict Hierarchical Order) trong doanh nghiệp Hàn Quốc thể hiện qua tính quyền uy ở người trên và tính phục tùng ở người dưới. Về hệ quả tích cực, nguyên tắc này tạo nên tính trật tự, kỷ luật nghiêm trong xã hội. Cá nhân có ý thức bổn phận cao. Tuy nhiên, mặt hạn chế là ở người trên, tính quyền uy dễ sinh ra thói độc đoán (dokdan); còn ở người dưới thì tính phục tùng có thể dẫn đến thói nhu nhược.

Lee Myung Bak trăn trở rất nhiều về thực tế đó trong thể chế doanh nghiệp Hàn Quốc:

"Điều làm tôi lo lắng nhất là tình cảm mang nặng tu tuoơng phong kiến phát sinh trong quan hẹ chủ tớ ở công ty" (tr. 29).

"Đó chính là sự quan liêu hóa tổ chức. Truờng hợp điển hình đó là mặc dù thời gian tan ca đã qua nhung mọi nguời trong công ty ai nấy cung đều không chịu rời khỏi ghế của minh mà cú chăm chăm để ý thái độ của sếp. Lúc đó có thể điều này đã trở thành phổ biến trong toàn bộ công ty nhung đối với tôi thì đó là một quang cảnh lạ mắt” (tr. 190).

Chàng trai trẻ Lee hào hứng hơn với hội trại nhân viên mới khi Tổng giám đốc cùng chơi bóng, hát và uống rượu với cấp dưới, hội trại "cho thấy tinh thần đoàn kết và bản sắc của Hyundai, thông qua đó duy trì tính bền vũng của nó" (tr. 110).

Kỷ niệm đáng nhớ nhất của Lee Myung Bak ở Malaysia là ngày lễ khởi công cây cầu Pinang. Để đón tiếp Thủ tướng Malaysia đến dự lễ, công ty Hyundai dựng khán đài có mái che và trải thảm sang trọng với ghế lớn ở giữa cho vị nguyên thủ. Viên thư ký Thủ tướng đến khảo sát hiện trường và yêu cầu: thứ nhất, "Phủ tấm che nắng cho cả năm ngàn người hoạc là tháo tấm che nắng ở chỗ ngồi của Thu tướng"; thứ hai, đem ghế giống như ghế người khác ngồi cho Thủ tướng - "Cái mông của Thủ tuoóng to hơn người khác sao?”. Lee Myung Bak tỉnh thức:

"Tôi đã bị sốc. Cũng có nhũ̃ng quan chức nghĩ đến nhân dân nhu thế. Dù đã đi khắp 
thế giới nhung tôi chura thế giới hóa được. Là người chuẩn bi lễ khởi công nhung tôi quá Hàn Quốc và quá quan liêu” (tr. 349).

Ông cũng "ghi lòng tac dạ" nhận xét của một nhân vật cấp cao của doanh nghiệp nước ngoài rằng: "Doanh nghiệp Hàn Quốc thật kỳ, nếu có một lãnh đạo được bổ nhiệm thì tài xế lái xe, ngườ đầu bếp, nhân viên đánh máy đi theo, tôi không thể nào hiểu được". Và khi trở thành Tổng giám đốc Huyndai, Lee Myung Bak đã "buộc các lãnh đạo đích thân lái xe". Chính ông cũng tự lái từ nhà đến nơi làm việc và từ nơi làm việc về nhà, "ban ngày khi có việc thì dùng người lái xe chung". Vào thời điểm đó, cả Hàn Quốc, không một công ty lớn nào mà lãnh đạo tự lái xe như ở Hyundai (tr. 270).

Về cách thức ra quyết định, vận hành trong doanh nghiệp Hàn Quốc phổ biến là đường dây phê chuẩn trung gian: trưởng phòng báo cáo trưởng bộ phận, trưởng bộ phận trình Phó Gíám đốc, Phó Giám đốc trình Giám đốc điều hành, lần lượt tới Phó Tổng Giám đốc, Tổng giám đốc, Chủ tịch tập đoàn. Lee Myung Bak thấy sự cồng kềnh đó làm mất thời gian, hơn nữa, "Nếu muời người xếp một hàng, người đầu nói một lời bảo truyền đạt cho người sau thì đến người cuối cùng sẽ sai biệt đến thành điều kỳ quăc". Ông thường xuyên gặp và lắng nghe ý kiến cấp dưới một cách trực tiếp: "Tôi nghĩ một người điều hành không có mỹ đưc nào lớn hơn là xủ lý công việc một cách hiệu quả và có ích" (tr. 271).

Khoảng cách quyền lực không chỉ liên quan tới sự phân biệt và thái độ ứng xử giữa người quyền lực (powerful) và người ít quyền lực (less powerful) mà còn liên quan đến căn cứ cho việc phân biệt các vị trí quyền lực cũng như khả năng, cơ hội cho việc vươn lên trên những nấc thang quyền lực. Nguyên tắc thăng tiến trong doanh nghiệp Hàn Quốc, theo thông lệ truyền thống dựa vào tuổi tác, thâm niên, dòng dõi, những quan hệ quen thân.

Khi còn là sinh viên, tự ứng cử Trưởng Hội Sinh viên khoa Thương mại, không hề có uy thế dòng dõi (vì chỉ là con của gia đình nông dân nghèo), không có sự trợ giúp từ các câu lạc bộ, hội đồng môn, hội đồng hương, Lee Myung Bak đã ý thức rằng giá trị thực sự của con người ở hành động và thành quả mà họ làm nên ("doing”) chứ không phải ở những yếu tố "tiên thiên", bản thể ("being") của họ.

Cuộc đời Lee Myung Bak là do ông làm nên, bằng hoài bão, quyết tâm, ý chí, nghị lực, tài năng và lao động của bản thân. Một trong những điều ông khâm phục ở Jeong Ju Young, vị Chủ tịch nhiều năm của tập đoàn Hyundai, là ở " $k \tilde{y}$ thuật dụng binh và dũng khi" của vị tướng "dám mạo hiểm sử dụng nhân tài", dám liên tục tin cậy và thăng chức vượt cấp cho một Lee Myung Bak không gia thế, không có tấm áo giáp của tuổi tác và không đầu tư cho các quan hệ quyền lực. Chủ tịch Jeong thường nói: "Tôi đã thăng chức cho anh khi nào, anh tụ thăng tiến đấy chư". Lee Myung Bak tin tưởng rằng nguyên tắc đó là một cốt lõi cho phát triển doanh nghiệp.

"Nhà doanh nghiệp có ý chi tiến thủ sã̃n sàng giao nhiệm vu cho người thật sự có năng lục làm việc chư không phải là tuổi tác hay quá trình hoạt động của ngườ đó" (tr. 128).

Phấn đấu cho thăng tiến, theo Lee Myung Bak, rốt cuộc, người ta phải cạnh tranh với chủ doanh nghiệp:

"Hãy coi chủ doanh nghiệp là đối tuợng cạnh tranh chứ không phải là đồng nghiệp. Hãy suy nghĩ nhu chủ doanh nghiệp, hãy làm việc nhu chủ doanh nghiệp và hãy nắm bắt điều đó. Hãy lập muc tiêu cao hon chủ doanh nghiệp. Lý do chủ tịch Jeong tìm gặp tôi mồi khi gặp nguy co là vì ông khắc sâu nhận thức: "Lee Myung Bak biết rõ bằng tôi, à không, hơn cả tôi, rằng công ty là của chính mình", (tr. 269-270).

Trên công trường của Hyundai tại Thái Lan, Tổng giám đốc Jeong Ju Young và Lee Myung Bak luôn là người thức dậy sớm nhất.

Khi hiệu quả quản lý, quản trị thay cho chủ nghĩa quyền uy, cạnh tranh lành mạnh trong nội bộ công ty trên những nấc thang vị thế là cạnh tranh về chủ nghĩa tập thể, về sự 
hết mình vì tập đoàn, tận hiến cho dân tộc.

\subsection{Nam tính và Nũ tính: Lý và Tình, Nguyên tắc và Linh hoạt}

Theo Hofstede,

"Một xã hội được gọi là nam tính khi các vai trò giới trên phuoong diện tình cảm được phân biệt rõ ràng: nam giới thuờng có tính quyết đoán, cúng rắn và chú trong đến thành công về mặt vật chất, trong khi đó, nũ giới thuờng khiêm tốn, dịu dàng, và quan tâm đến chất luợng cuộc sống nhiều hơn.

Một xã hội được gọi là nũ tính khi vai trò giới tính trên phuoong diện tình cảm không phân tách rõ ràng: cả nam giới và nũ giới đều có thể có đức tính khiêm tốn, dịu dàng và quan tâm đến chất luợng cuộc sống" (Geert Hofstede et al, 2013: 189).

Nghiên cứu của Hofstede cho thấy văn hóa doanh nghiệp Hàn Quốc thể hiện chủ nghĩa nữ tính (tình cảm, quan tâm chất lượng cuộc sống hơn), khác với chủ nghĩa nam tính (quyết đoán, chú trọng thành công vật chất hơn) trong văn hóa doanh nghiệp Hoa Kỳ.

Khá nhiều công trình nghiên cứu của các học giả Hàn Quốc và nước ngoài nhất trí cho rằng người Hàn nói chung trọng Tình (Jeong), coi trọng những cư xử ấm áp Tình người (Injeong), nhấn mạnh tầm quan trọng của Gibun (tâm trạng, cảm xúc, trạng thái tinh thần). Người Hàn thường cũng đề nghị "chiếu cố" ("buthak hapnida"), giải quyết công việc dựa trên sự ưu đãi những quan hệ cá nhân bên cạnh luật thì lại có "lệ", ưu đãi, "đặc cách" cho người thân quen. Đặc điểm trọng tình ảnh hưởng đến mạng lưới nhân sự trong các tổ chức, công ty của người Hàn thường dựa trên tin cậy riêng tư của những quan hệ thân thiết, trong đó, có vai trò quan trọng là hệ thống FAR (Family - Gia đình, Alumni - Bạn đồng môn, Regionalism - Chủ nghĩa địa phương). Khoảng $60 \%$ các nhà quản lý cao cấp ở 6 Chaebol hàng đầu (Huyndai, Samsung, LG, Daewoo, Ssangyong, Sunkyong) xuất thân từ trường Đại học Quốc gia Seoul. Việc tổng thống Roh Tae Woo cùng hai vị tổng thống trước ông này đều đến từ Kyungsang doh đã khiến số chính khách quê ở vùng này chiếm số lượng lớn trong chính phủ. Tương tự khi Kim Yong Sam làm tổng thống thì nhân viên cao cấp chính phủ lại có số lượng rất lớn từ Chungla quê ông. Nói cách khác, có thể thấy tính chính thống của những tổ chức phi chính thống này trong văn hóa dân tộc nói chung, văn hóa doanh nghiệp nói riêng của Hàn Quốc. Những quan hệ tương hỗ mang tính đạo đức và phi chính thống được coi trọng và quan tâm phát triển bên cạnh những quan hệ chính thống, mang tính luật pháp, hợp đồng vốn là đòi hỏi của quản trị kinh doanh hiện đại.

Lee Myung Bak là người đấu tranh không khoan nhượng với thói quen truyền thống đó.

Khi giữ chức Trưởng phòng Quản lý máy móc công nghiệp nặng, Lee Myung Bak thẳng thừng từ chối lời đề nghị của phu nhân Tổng giám đốc về việc giải quyết công ăn việc làm cho con cái người đồng hương của bà:

"Phu nhân ở Cheongwoondong trở về vói vẻ mặt thất thểu."

"Tôi đã không lùi buoóc, tuân thủ nguyên tắc chỉ sủ dụng người theo đúng tiêu chuẩn. Không chỉ phu nhân của Tổng giám đốc mà nhũng ngườ ở quê tôi, nhũng người bà con của tôi nhờ vả đều bị khước tù̀" (tr. 142).

Quan điểm của ông rất rõ ràng:

"Không có một đầu sỏ tài phiệt nào sủ dụng người của mình bằng quan hệ tình cảm riêng tư như tình đồng hương, tình đồng môn, Phải biết cách sử dụng nguoòi một cách khoa học mà không có ngoại lệ nào" (tr 34).

"Lối suy nghĩ thói quen xem mọi quan hệ xã hội bắt nguồn tù quan hệ tình cảm địa phuoong, tình đồng môn nếu lan tràn sẽ gây bệnh cho xã hội" (tr.35).

Mặt khác, Lee Myung Bak được bạn bè, đồng nghiệp đánh giá là "người có tình hơn ai hết" (tr.154).

Ông kể lại kỷ niệm đáng nhớ với Tổng Giám đốc Lim khi ông chỉ là trưởng bộ phận ở phòng sửa chữa máy móc công nghiệp nặng. Với tư cách đại diện doanh nghiệp bán vật liệu cho Hyundai, lần nào ghé văn phòng, Tổng giám đốc Lim cũng khiêm tốn, chào cả người bảo vệ, đối xử với công nhân như đồng nghiệp. 
Có lần nhân Tết Trung thu (dịp lễ tết lớn thứ hai trong năm của người Hàn, sau Tết Nguyên đán), Tổng giám đốc Lim tặng toàn bộ nhân viên mỗi người một chiếc sơ mi. Lee Myung Bak chỉ thị thu hồi toàn bộ số áo và trả lại cho ông Lim. Sau đó, Tổng giám đốc Lim hẹn gặp Lee ở một quán ăn bên ngoài để trò chuyện "không về công viẹc, mà về nhân sinh", "không phải với tu cách người giao hàng mà với tu cách người đi trước". Tổng giám đốc Lim nói:

"Trong thờ gian qua, tôi chỉ biểu thị tấm lòng của minh trong phạ vi cho phép đối với những ngườ đã giúp công việc của tôi. Tôi không làm gì sai trái để đưa hối lọ hay ban ân huệ cho nhũng ngườ đó. Nhung kể tù khi anh Lee về đây, văn phòng bảo vệ đã làm theo nguyên tắc và áo so mi cũng trở về chủ cũ. Truơong bộ phận Lee quá lạnh lùng.

Hoàn hảo và chính trục cũng quan trọng nhung nếu không có đức và nhân tình ấm áp thì không thể trở thành nguời vĩ đại. Nếu không có sụ mềm dẻo chẳng khác gì cái máy" (tr. 265).

Lee Myung Bak ghi nhớ mãi những lời gan ruột ấy.

Trong khi kiên quyết từ chối cấp “đặc ân” cho những họ hàng, đồng hương, đồng môn của mình, Lee Myung Bak lại đầy trách nhiệm bù đắp cho gia đình những người công nhân bình thường nhất từng hiến dâng phụng sự cho công ty. Hình ảnh quản đốc Choi làm việc tận tụy mồ hôi nhễ nhại trên công trường ở Thái Lan, cuối cùng bị những người bản địa phản đối chỉ thị công việc bắn chết, hai mươi năm sau vẫn nhức nhối trong trái tim Lee Myung Bak và ông đã nhận con trai của quản đốc này vào làm ở Hyundai. Ông cũng nhận vào Hyundai con trai của ông Hwang, người phục vụ Huyndai cả 30 năm, dù chỉ là lái xe, từ Iraq trở về quê hương gặp tai nạn máy bay, chết trên bầu trời Myanmar.

"Cũng có lúc tôi giá nhu tôi có thể chết thay họ. Chúng ta sống trên sụ hy sinh của nhũng ngườ đang làm việc và ra đi không tên tuổi. Khi công ty và xã hội không quên cái chết của ho thi có một thế giới chân chính đáng sống" (tr. 259).
Mở ra thị trường quốc tế, Lee Myung Bak giành được nhiều hợp đồng lớn, nhiều thỏa thuận hợp tác quan trọng với các đối tác hàng đầu của Iraq, Malaysia, Liên Xô... Bí quyết giúp ông thành công, vượt lên trên bao thách thức gay go từ những khác biệt chính trị, kinh tế, xã hội, công nghệ giữa Hàn Quốc và các nước này không chỉ là ở những luận chứng kinh tế thuyết phục mà chính bằng ý chí quyết tâm sắt đá đi cùng tấm lòng chân thành, xử sự ấm áp nghĩa tình trên lập trường win-win cho cả hai phía.

"Iraq không có chế độ đưa môi giới bản xứ vào việc nhận thi công. Để gặp một nhà lãnh đạo của đất nước đi đầu về thanh liêm và đạo dức nhu thế thì không có phuoong pháp nào khác ngoài việc kêu gọi tính nhân văn (tr.222). "Kết cuc, cuộc hẹn (vói Thị truớng Wahab) lúc đầu giới hạn trong 10 phút được kéo dài thành 2 tiếng. Chúng tôi đã phát hiện có nhiều đồng cảm tù̀ nhãn quan đất nước, nhiệt tình làm việc, lịch sử của Trung Đông và châu Á và cả nhũng việc cá nhân. Nhu thể chúng tôi đã quen nhau cả 10 năm. Mô hình tàu rùa thấm đượm linh hồn tướng quân Lee Sun Sin của Hàn Quốc đã được đặt trong phòng làm việc của nhà Cách mang trẻ của Bagdad" (tr.224).

"Vùng Bắc cưc được tan ra bởi vodka. Giũa nhũng chai vodka chúng tôi đã cảm nhận được nhũng gì thuộc về tình cảm con người" (tr. 322).

Suốt đời mình, Lee Myung Bak đã kết hợp chủ nghĩa nguyên tắc cứng rắn, nghiêm ngặt, trung thành tuân thủ những đòi hỏi công lý, chính nghĩa, với chủ nghĩa nhân văn của trái tim nhân hậu, mềm mỏng: "Trước hết hãy thấm nhuần kỹ thuật co bản đặt trên nguyên tắc rồi trên co sở đó phát huy tính linh hoạt, khéo léo, tụ do" (tr. 266).

2.4. Không né tránh sự bất định: Dám chấp nhận, đương đầu để chiến thắng nhũng thách thức, ruii ro

Theo Hofstede,

"Tâm lý tránh bất định có thể được định nghĩa là phạ vi mà các thành viên của mọt nền văn hóa cảm thấy bị đe dọa trong nhũng 
tình huống mập mờ hoặc không quen thuộc. Cảm giác này được phản ánh qua thái độ căng thẳng, lo lắng và đòi hỏi về khả năng có thể tiên đoán được. Yêu cầu cần phải có các quy định thành văn và bất thành văn" (2013: 252).

Nghiên cứu của Hofstede cho thấy chỉ số tránh sự bất định trong văn hóa doanh nghiệp Hàn Quốc thuộc loại rất cao, trong khi Hoa Kỳ có chỉ số tránh bất định khá thấp.

Khá nhiều công trình nghiên cứu của các học giả Hàn Quốc và nước ngoài cũng đã đề cập đặc điểm văn hóa Hàn Quốc tránh bất định cao thể hiện qua sự ưa thích những luật lệ, quy định, quy tắc chi tiết, cụ thể, tỉ mỉ; sự xem trọng kỷ luật giờ giấc, thời hạn; áp lực công việc lớn; xu hướng nhân viên mong muốn gắn bó lâu dài với công ty, tránh cái bấp bênh, thay đổi...

Trong Không có thần thoại, tiêu biểu cho tính tuân thủ quy tắc, có thể kể đến câu chuyện về quan hệ giữa Lee Myung Bak, lúc đó chỉ là kế toán viên với giám đốc công trường. Nhân viên, công nhân bận rộn trên công trường nên thường đến nhận ứng lương sau 5 giờ chiều. Lee hiểu hoàn cảnh đã giúp họ được tiện lợi. Nhưng ông giám đốc không vừa lòng: " $\hat{E}$, thằng kia, kế toán gì mà sau 5 giờ vẫn cho ưng lương vậy. Ngân hàng sau 5 giờ có làm việc đâu?". Lee thấy ông giám đốc cố chấp nhưng không phản đối. Sau đó, khi chính giám đốc đến yêu cầu phát tiền sau 5 giờ thì Lee kiên quyết không chấp hành.

"Nhưng mà tao là giám đốc ở đây.

"Nếu giám đốc tụ minh chống lại nguyên tắc mà minh đã đề ra thì bất cú ai cũng có thể chống lại nguyên tắc đó. Do đó, tuyệt đối không được ưng luơng bây giờ".

Tôi đã linh tính ông sẽ trả đũa tôi vì chuyện này. Tuy nhiên, sau đó, nguợc lại, ông có vé thận trọng hơn trong cu xủ với tôi... Một ngày nọ, khi chở tôi ra ngân hàng, trên đường đi, ông đã nói:

"Cái thằng này, một ngày nào đó mày sẽ trở. thành một nhân viên cốt cán trong công ty" (tr. 114-115).

Rốt cuộc, câu chuyện cho thấy không phải một kế toán viên khư khư bám lấy các quy tắc mà đúng hơn là một người trẻ tuổi khí phách, sẵn sàng chấp nhận rủi ro bị cấp trên "trù úm" hoặc sa thải.

Hành trình trưởng thành của Lee Myung Bak là sự chuyển biến từ một đứa trẻ nhà nghèo "e thẹn và nhút nhát" thành con người "hướng ngoại và can đảm".

Không có tiền của, không có sự bao bọc của các quan hệ cá nhân, Lee Myung Bak được nhận vào làm việc ở Hyundai nhờ sự thuyết phục trong buổi phỏng vấn. Khi Tổng giám đốc Jeong hỏi: “Theo anh nghĩ thì xây dưng là gi??", Lee đã trả lời: “Tôi nghĩ đó là sáng tạo, sáng tạo tù không thành có" (tr. 107). Câu hỏi Lee không ngờ tới nên câu trả lời có phần đột nhiên, song, chính là câu trả lời vụt ra tù ấp ủ sâu kín trong tâm thức lâu dài. Vượt trên hoàn cảnh khó khăn, trong cuộc đời, trong sự nghiệp, Lee Myung Bak đã không ngừng phải sáng tạo từ không thành có. Đi cùng Hyundai, ông đã góp phần không ngừng sáng tạo tù̀ không thành có một tập đoàn lớn của Hàn Quốc với uy danh quốc tế. Chấp nhận nghĩa "sáng tạo tù không thành có" đó, Lee Myung Bak không phụ thuộc vào đường xưa nếp cũ, không e ngại, né tránh sự bất định.

Ông ngày càng trở nên mạnh mẽ, dám chấp nhận mọi bất trắc, rủi ro, tiến tới:

"Khi bắt tay vào công việc nào đó, suy nghĩ giũa cái làm được và cái không làm được là khoảng cách khá lớn. Suy nghĩ của nhũng người nói là không làm được thì bị dính chặt vào lý do không thể. Người suy nghĩ làm được thì cho dù có khả năng chỉ $1 \%$ cũng cố nắm lấy.

Khả năng có thể chỉ 1\%, hay thậm chí cho dù công việc thất bại $100 \%$ thì ngườ làm công việc đó sẽ còn lại kinh nghiệm. Nhung đối với người không làm, tù bỏ tù đầu thì không còn lại cái gì. Tôi tính khoảng cách này là 50:0. Thật sự là khoảng cách lớn. Lý do phải có ý thức thư thách công việc một cách quả quyết và tích cực nằm ở đây" (tr. 224).

Trên cùng một lập trường dám đương đầu thử thách, chấp nhận rủi ro như vậy mà 
ông kiên quyết cùng Hyundai đi con đường của doanh nghiệp cạnh tranh chứ không phải doanh nghiệp độc quyền dựa vào bảo hộ của nhà nước. Lee Myung Bak nhiều lần đối đầu cả với những cơ quan quyền lực cao nhất của chính phủ. Ông tranh luận nảy lửa với quyền lực tuyệt đối của Ủy ban chính sách khẩn cấp bảo vệ quốc gia:

"Doanh nghiệp độc quyền khi mói xuất phát rất tốt nhung sẽ gặp hạn chế. Nhung doanh nghiệp trong xã hội canh tranh thì phát triển vô cùng.

Logic kinh tế của tôi là chỉ có nền kinh tế sống sót dựa vào luật công bằng" (tr. 187198).

Chấp nhận thách thức, rủi ro, dám đột phá những tiềm năng, những cách thức mới, những cái chưa từng có tiền lệ, Lee Myung Bak đã đóng góp quyết định cho Hyundai vươn lên thành doanh nghiệp hàng đầu của Hàn Quốc đồng thời là doanh nghiệp tiên phong đầu tư ra nước ngoài.

\section{5. Định hướng dài hạn: Kiên trì nỗ lực cho} Hàn Quốc đi tới toàn cầu

Theo G. Hofstede, chủ nghĩa thực tiễn / chủ nghĩa thực dụng (Pragmatism) thể hiện cách thức mà một nền văn hóa duy trì những gắn kết với quá khứ của nó trong khi đương đầu với những thách thức hiện tại và tương lai.

"Định hướng dài hạn biểu thị cho bồi duỡng đạo đức huoóng tới nhũng phần thướng trong tuoong lai, đặc biệt là sư kiên nhẫn và tiết kiệm. Định huớng ngắn hạn biểu thị cho sụ bồi duỡng đạo đức liên quan tới quá khư và hiện tại, đặc biệt đối với lòng tư trọng và thực hiện các nghĩa vu xã hộl" (Geert Hofstede et al, 2013: 309).

Nghiên cứu của Hofstede cho thấy chỉ số định hướng dài hạn của Hàn Quốc rất cao, đạt đến mức tuyệt đối, khác với chỉ số thấp thể hiện định hướng ngắn hạn của Hoa Kỳ.

Khá nhiều công trình của các học giả Hàn Quốc và nước ngoài nhất trí về tính cách kiên trì, nhẫn nại, nỗ lực cho tương lai xa trong văn hóa Hàn Quốc truyền thống. Kim chi không chỉ là một món ăn đặc trưng mà còn có thể xem là biểu tượng cho dân tộc phải ứng phó với mùa đông khắc nghiệt kéo dài. Hoa Mugung (Hoa Vô cùng) được chọn làm quốc hoa do đặc tính vẫn nở trên núi cao qua kỳ băng giá. Câu chuyện huyền thoại lập quốc cũng tô đậm sức mạnh tinh thần ấy với hình tượng con gấu trì chí giữ kỷ luật giam mình trong hang đá đủ trăm ngày, chỉ ăn tỏi và ngải cứu để được thành người, thành Ungnu (Hùng Nữ) cùng với con trai Thiên đế sinh ra tổ tiên dân tộc Hàn.

Trong Không có thần thoại của Lee Myung Bak, định hướng dài hạn không dừng ở thái độ nhẫn nại, chịu đựng mà tràn đầy hoài bão lớn lao, tràn đầy sức mạnh cương cường, phấn đấu cho những kỳ tích phi thường, đem Tổ quốc lên đài cao vinh hiển, vượt khỏi đường chân trời của dân tộc vươn ra thế giới, vươn tới toàn cầu. Doanh nghiệp không chỉ nhắm tới lợi nhuận kinh tế mà tích hợp kinh tế với chính trị, kinh tế với văn hóa, xã hội, ngoại giao.

Khi làm doanh nhân cũng như khi trở thành Tổng thống, Lee Myung Bak luôn tâm niệm rằng "Động lực kéo đất nước đi lên là chinh kinh tế chư không phải chính trị" (tr. 21). Tuy nhiên, khác với tư tưởng "duy kinh tế cực đoan" của Park Chung Hee ("Châu Á phải có kinh tế đi trước cùng với bàn tay sắt của chính quyền"), theo Lee Myung Bak, chỉ có đất nước phồn vinh, nhân dân hạnh phúc khi nền dân chủ được đảm bảo. Từ thời sinh viên, Lee Myung Bak đã lãnh đạo phong trào đấu tranh đòi dân chủ, bị bắt bớ, giam cầm. Lần cuối cùng ông gặp Park Chung Hee là vào ngày 20/10/1979, chưa đầy một tuần trước ngày nhà độc tài bị ám sát. Chứng kiến cảnh lãnh đạo các giới bị triệu đến Nhà Xanh, phải học thuộc lòng nội dung phát biểu mà những quan chức Phủ Tổng thống ghi sẵn trong phong bì trao cho mỗi người, Lee Myung Bak suy nghĩ về trách nhiệm của những người phụ tá: giá như họ đã bảo vệ Tổng thống một cách đúng 
đắn, đã tổ chức những "cuộc đối thoại với nhân dân" có ý nghĩa chính đáng hơn chỉ là hình thức giả dối thì đã không dẫn đến sự biến ngày $26 / 10$ (tr. 181).

Khi nỗ lực mang Hyundai đến Iraq, Lee Myung Bak không chỉ quyết tâm "làm chảy ngược dòng đô la dầu lựa tù Trung Đông về Hàn Quốc" mà còn chân thành hy vọng hai phía có thể "làm việc trên lập truờng cùng đứng lên tù nghèo đói", qua đó những "kinh nghiệm vực dậy từ nghèo đói" của Hàn Quốc có thể được sẻ chia (tr. 223).

Khi nỗ lực mang Hyundai đến Liên Xô, Lee Myung Bak muốn khởi sự bắc cây cầu hợp tác đến một nửa địa cầu của những nước Cộng sản:

"Trung Quốc cũng nhu các bang liền nhau của Liên Xô cũ hay Siberia theo địa lý thì gần với nuớc ta biết bao nhiêu. Chúng ta làm bạn với Mỹ ở bên kia Thái Bình Dưong, nguợc lại với hai nuớc lón ở khoảng cách rất gần thì lại coi nhau nhu kẻ thù gần nửa thể kỷ, một sư thật đáng tiếc. Để kẻ địch dưới đầu thì làm thế nào có thể đón nhận thế kỷ 2l" (tr. 315).

Điều mà Lee Myung Bak còn nuối tiếc trong sự nghiệp của mình là những dự án hợp tác của Hyundai với Triều Tiên có thể giúp đẩy nhanh tiến trình thống nhất bán đảo Hàn, cuối cùng, chưa được thực hiện - "lý luận kinh tế bị hy sinh vì lý luận chính trị" (tr. 345). "Một số nguoờ đặt vấn đề chi phí thống nhất và dư đoán nếu được thống nhất thì kinh tế của cả Nam và Bắc sẽ bị lạc hậu, nhung tuyệt đối không phải nhu vậy. Hợp tác kinh tế không phải là chúng ta giúp Bắc Hàn một chiều. Không phải là viện trọ mà là hợp tác kinh tế. Cả Nam và Bắc cùng phát triến" (tr. 345).

"Tôi ước mo dân tộc minh có thể tiến vào phuoong Bắc và trở thành trung tâm khối kinh tể Đông Bắc Á bởi sư hợp tác Nam Bắc Hàn" (tr. 343).

Định hướng dài hạn của Lee Myung Bak không gì khác hơn là mở rộng nhãn quan, vượt trên những định kiến, phấn đấu cho phát triển bền vững và hội nhập toàn cầu.
2.6. "Văn hóa quân sụ", Chủ nghĩa khắc kỷ và "Thanh phú luận"

Theo Hofstede, thái độ thoải mái / hưởng thụ "đại diện cho xu huoóng cho phép tụ do, hài lòng với nhũng khao khát con người tư nhiên và bản năng về mắt tận huởng cuộc sống và vui choi". Thái độ Kiềm chế / Khắc kỷ "phản ánh ý thức cho rằng sụ hài lòng đó cần phải kiềm chế và đura vào khuôn khổ bằng nhũng thông lệ xã hội hà khắc" (Geert Hofstede et al, 2013: 363).

Nghiên cứu của Hofstede cho thấy Hàn Quốc có thiên hướng khắc kỷ, kiềm chế khác với Hoa Kỳ thoải mái, hưởng thụ.

Khá nhiều công trình nghiên cứu của các học giả Hàn Quốc và nước ngoài cũng đã phân tích ảnh hưởng Nho giáo trong thái độ "khắc kỷ phục lễ" của Hàn Quốc truyền thống cũng như phân tích văn hóa quân sự trong quản trị kinh doanh của Hàn Quốc hiện đại.

Trong hồi ký của mình, Lee Myung Bak không ít lần miêu tả Jeong Se Yeong như một vị tướng nơi chiến địa:

"Tổng giám đốc Jeong trong đồng phục in chũ "Xây dưng Hyundai" đang ngồi ở giữa hàng ghế. Ông có vé đầy tư tin và nghiêm nghi trông giống nhu là một tur lệnh quân đội dã chiến hơn là tổng giám đốc doanh nghiẹp" (tr. 107).

(Chủ tịch Jeong và tôi) "đi xem hiện truờng xây dụng công ty Hyundai (ở Bagdad) nằm trong tầm oanh tạc. Dù ở noi chiến truờng, chủ tịch Jeong cũng không chùn buớc. Đúng hơn là liều minh xông vào nguy hiểm. Ngài có bộ dạng tuớng quân lỗi lạc đi xem hiện truờng Iraq đang chiến tranh. Nếu chủ tịch Jeong có điều gì không hài lòng thì ngài la lớn: "Này, tù chức đì" (tr.235-236).

Lee Myung Bak giải thích đặc điểm quân sự trong văn hóa quản lý ở Hyundai một mặt, là di sản của cuộc chiến tranh Triều Tiên mới đi qua không lâu, hậu quả của việc Hàn Quốc tham chiến ở Việt Nam, những ảnh hưởng của thể chế độc tài, mặt khác, là do công ty suốt thời gian dài phải dốc sức vượt lên từ một doanh nghiệp tẻ nhạt, quyết ra khỏi nghèo đói, thậm chí quyết xác lập những kỷ lục phi thường, quyết vươn ra thị trường quốc tế. 
"Phòng quản lý máy móc công nghiệp nạng, nơ chi viện cho công trình xây dưng đường cao tốc Gyeongbu, luôn bận rộn, khó thở nhu trong thời gian chiến tranh đã phải tất bật trong vai trò là xuơơng chế tạo vũ khi phuc vu cho quân đọi. Vì vây mà tính kỷ luật và sư tập trung cao độ đã được đặt lên hàng đầu. (tr. 134).

Trong thời gian thi công để "hoàn thành ky luc đường cao tốc (Gyeongbu) với giá rẻ nhất và trong thời gian nhanh nhất thế giới", "Tổng giám đốc (Jeong Ju Yeong) đã ngủ trên chiếc givờng dã chiến với chiếc chăn đắp và tập trung vào công việc nhu người quản đốc" (tr. 135).

Bản thân Lee Myung Bak, ngay cả khi Hyundai đã hùng mạnh và ông đã giữ những chức vụ cao cấp, không khi nào không phải chạy đua hết sức với thời gian:

"Tôi nhảy vào thị truờng nuoóc ngoài nhu bãi chiến truờng và làm việc ngày 18 tiếng, chura bao giờ ngủ quá 4 tiếng".

"Có lẽ không có người quản lý tối cao nào của công ty lón trưc tiếp nhận mọi cuộc điện thoại quốc tế vào nửa đêm nhu tôi. Vi chênh lệch múi giờ, nếu lõ nhũng cuộc điện thoại đêm ở tru sở chính và ở nước sở tại thì cộng lại sẽ muộn 2 ngày. Hiện nay trên thế giới nhiều công việc phán xét tình hình chỉ trong vài phút mà chờ 2 ngày thì dài và chán biết chùng nào" (tr. 272).

Lee Myung Bak không khi nào có điều kiện quan tâm gia đình cũng như cho sức khỏe chính mình. Chỉ một lần ông đi nghỉ cùng vợ và một lần cùng cả các con. Lần thứ nhất về quê để suy nghĩ khi được bổ nhiệm Tổng giám đốc. Lần thứ hai đến đảo Jeju, trăn trở quyết định rời bỏ Hyundai. "Cả hai lần đều liên quan công việc của tôi chư chura bao giờ tôi có chuyến đi du lịch thuần túy với gia đình" (tr. 301). Viêm gan mãn tính ở mức trầm trọng, nhưng ông nói với bác sĩ: "Tôi thích làm việc và chết chứ không thể nằm bệnh viện chờ chết" (tr. 284). Hơn 10 năm ông kiên cường chống chọi trong công việc, cuối cùng xét nghiệm không còn virus. Các bác sĩ kinh ngạc: "Trong mấy chục ngàn người mói có một người tụ nhiên chũa trị khỏi. Chủ tịch Lee chính là truờng hơp đơ". Lee Myung Bak có lý giải của riêng mình:
"Đối với y học được giải thích là đẩy lùi bệnh viêm gan do thể chất đặc biệt, nhung tôi không chỉ hiểu theo nhu thế. Có phải do miệt mài công việc không? Tôi sống vì công việc nhung công việc đó cũng đã cứu mạng sống của tôi" (tr. 284).

Tuy nhiên, chính Lee Myung Bak không nghĩ tinh thần làm việc như vậy là khắc kỷ. Lao động, cống hiến, với ông, là lý tưởng sống nên có thể trở thành chính niềm vui chứ không phải sự chịu đựng.

"Khi ai sai bảo việc gì làm một cách thu động thì sẽ bị căng thẳng. Tôi làm việc để đẩy lùi căng thẳng" (tr. 278).

Liên quan đến thái độ khắc kỷ, kiềm chế hay thoải mái, hưởng thụ là cách người ta kiếm tiền và ứng xử với tiền bạc, của cải. Xã hội truyền thống Hàn Quốc chịu ảnh hưởng thống lĩnh của Nho giáo, đặt Danh đối lập với Lợi, gắn giàu có với tham lam, bóc lột, còn thanh sạch phải khó nghèo. Lee Myung Bak thấy giáo điều đạo đức đó đã lỗi thời:

"Có lúc, trong xã hội chúng ta nghĩ rằng nhiều tài sản là làm ăn bất chính và nhũng người nhiều tài sản đó được xem nhu tội nhân. Một nhận thức nguy hiểm chết người. Nếu suy nghĩ này thống trị xã hội thì không thể nâng cao "chất luợng cuộc sống" là muc tiêu tích cưc của quốc gia" (tr. 305).

"Điều cần thiết của xã họi chúng ta không phải là "thanh bần luận" mà là "thanh phú luận". "Tục ngũ của chúng ta có câu "Kiếm tiền chật vật, tiêu tiền đường hoàng", bây giò phải viết lại thành "Kiếm tiền đứng đắn, tiêu tiền đường hoàng”. Có nghĩa là tài sản gom góp một cách trong sạch và hợp pháp để sủ dụng đưòng đuoòng chính chinh" (tr. 306).

Kiểm kê tài sản mình có khi rời Hyundai, ông tự hào vì được đãi ngộ chính đáng cho ba mươi năm làm việc với toàn bộ sức lực của một nhà kinh doanh chuyên nghiệp. Sau cùng, vợ chồng ông quyết định không chuyển quyền thừa kế cho các con mà dùng tài sản đó lập quỹ hỗ trợ nghiên cứu: "Quỹ nghiên cứu Đông Á là sụ thực hành thanh phú luận đầu tiên của tôi" (tr. 308).

Vậy nên, nếu người ta thấy ở Lee Myung Bak một cái gì như là chủ nghĩa khắc kỷ Phương 
Đông thì trong chiều sâu, đó là sự hy sinh những quyền lợi trước mắt của cá nhân, hiến dâng, phụng sự tương lai lâu dài của dân tộc.

\section{Hệ giá trị Lee Myung Bak đối chiếu với} đặc điểm văn hóa doanh nghiệp Hàn Quốc theo kết quả nghiên cứu của Hofstede

Những giá trị văn hóa doanh nghiệp, văn hóa doanh nhân qua hồi ký Không có thần thoại của Lee Myung Bak có nhiều điểm chung với kết quả nghiên cứu của Hofstede đối với nhân viên các công ty IBM ở Hàn Quốc [ở các chiều kích (2), (5), (6)] nhưng đồng thời cũng có những điểm xa chệch, thậm chí tương phản [ở các chiều kích (1), (3), (4)].
Bak. Ở khá nhiều chiều kích, có thể thấy hệ giá trị Lee Myung Bak đã tích hợp những ảnh hưởng truyền thống Phương Đông và hiện đại Phương Tây.

Trong những ảnh hưởng truyền thống, ông bố gia giáo điển hình, siêng năng toàn tâm toàn ý cho công việc, đề cao sức mạnh đạo đức; và nhất là bà mẹ cùng sự nghèo khó đã trở thành người Thầy thực sự cho Lee Myung Bak. Mẹ ông cầu nguyện cho đất nước, cho xã hội, họ hàng, hàng xóm rồi mới đến cho gia đình và không xin gì cho bản thân. Mẹ ông luôn dạy ông "phải hành động đường đường chính chính trong moi hoàn cảnh khó khăn nghiệt ngã̃" (tr. 34). Mệ ông dạy ông bổn phận

\begin{tabular}{|c|c|c|c|}
\hline STT & $\begin{array}{c}\text { Những giá trị Hàn Quốc } \\
\text { (theo nghiên cứu của } \\
\text { Hofstede) }\end{array}$ & $\begin{array}{l}\text { Những giá trị trong Không có } \\
\text { thần thoại của Lee Myung Bak }\end{array}$ & $\begin{array}{l}\text { Những giá trị Hoa Kỳ (theo } \\
\text { nghiên cứu của Hofstede) }\end{array}$ \\
\hline 1 & $\begin{array}{l}\text { Khoảng cách quyền lực cao } \\
\text { (High Power Distance) }\end{array}$ & $\begin{array}{l}\text { Khoảng cách quyền lực thấp } \\
\text { (Low Power Distance) }\end{array}$ & $\begin{array}{l}\text { Khoảng cách quyền lực thấp } \\
\text { (Low Power Distance) }\end{array}$ \\
\hline 2 & $\begin{array}{l}\text { Chủ nghĩa cộng đồng } \\
\text { (Collectivism) }\end{array}$ & $\begin{array}{l}\text { Chủ nghĩa cộng đồng } \\
\text { (Collectivism) }\end{array}$ & $\begin{array}{l}\text { Chủ nghĩa cá nhân } \\
\text { (Individualism) }\end{array}$ \\
\hline 3 & $\begin{array}{l}\text { Nữ tính } \\
\text { (Femininity) }\end{array}$ & $\begin{array}{l}\text { Nam tính (Masculinity) } \\
\text { và Nữ tính (Femininity) }\end{array}$ & $\begin{array}{l}\text { Nam tính } \\
\text { (Masculinity) }\end{array}$ \\
\hline 4 & $\begin{array}{c}\text { Tránh sự bất định rất cao } \\
\text { (Very High Uncertainty } \\
\text { Avoidance) }\end{array}$ & $\begin{array}{l}\text { Tránh sự bất định thấp } \\
\text { (Low Uncertainty Avoidance) }\end{array}$ & $\begin{array}{c}\text { Tránh sự bất định khá thấp } \\
\text { (Rather Low Uncertainty } \\
\text { Avoidance) }\end{array}$ \\
\hline 5 & $\begin{array}{c}\text { Định hướng dài hạn / } \\
\text { Chủ nghĩa thực tiê̂n } \\
\text { (Pragmatism) }\end{array}$ & $\begin{array}{l}\text { Định hướng dài hạn / } \\
\text { Chủ nghĩa thực tiễn } \\
\text { (Pragmatism) }\end{array}$ & $\begin{array}{c}\text { Định hướng ngắn hạn / } \\
\text { Nguyên tắc } \\
\text { (Normative) }\end{array}$ \\
\hline 6 & $\begin{array}{l}\text { Kiềm chế / Khắc kỷ } \\
\text { (Restraint })\end{array}$ & $\begin{array}{l}\text { Kiềm chế / Khắc kỷ } \\
\text { (Restraint) }\end{array}$ & $\begin{array}{l}\text { Thoải mái / Hưởng thụ } \\
\text { (Indulgence) }\end{array}$ \\
\hline
\end{tabular}

Hình 2. So sánh 6 chiều kích văn hóa thể hiện qua hồi ký Không có thần thoại của Lee Myung Bak với những giá trị Hàn Quốc và Hoa Kỳ theo nghiên cứu của Hofstede

Phần lớn trong những điểm xa chệch, tương phản chính là những điểm khiến hệ giá trị Lee Myung Bak gần hơn với hệ giá trị Hoa Kỳ / Phương Tây. Và ngay ở những điểm tương đồng với hệ giá trị Hàn Quốc / Phương Đông, vẫn có thể thấy khá rõ dấu ấn sự tái cắt nghĩa, tái cấu trúc trong hệ giá trị Lee Myung phục vụ, giúp đỡ mọi người, không được nhận đền ơn: "Nếu nguời nghèo cú trông đợi vào sụ" giúp đõ hay trả on của nguời giàu thì suốt đời không bao giờ thoát khỏi cái nghèo của họ" (tr. 54). Cái nghèo cứ bám riết gia đình khiến Lee Myung Bak phải trải qua thưở thơ ấu và suốt thời học trò cực nhọc nhưng chính cái 
nghèo đã rèn giũa trong ông ý chí, nghị lực sắt đá cùng tính cách phấn đấu bất khuất và lao động kiên cường.

Trong những ảnh hưởng hiện đại, Lee Myung Bak chủ động học hỏi từ kinh nghiệm, cả thành công lẫn thất bại, của các nước, từ các nước phát triển đến các nước đang phát triển. Ông xem Nhật, Đức như những mẫu mực về tinh thần siêng năng và kỷ luật lao động; ông khâm phục quyết tâm đẩy nhanh hiện đại hóa để xây dựng quốc gia tự chủ của Thủ tướng Malyasia; ông thấm thía hạn chế của một số doanh nghiệp quốc gia độc quyền Ấn Độ như vết xe đổ mà Hàn Quốc không được dẫm chân theo...

"Mỗi lần ra nước ngoài, tôi đều cảm nhận được sư thay đồi" (tr. 35).

"Trong xã họi, nhóm tiếp cận và thích úng sớm nhất với quốc tế hóa chính là nhũng nhà doanh nghiẹp" (tr. 37).

"Doanh nghiệp chúng ta đã truởng thành và sánh vai cùng các doanh nghiệp hàng đầu thế giới nhưng chính trị thì còn đang tranh giành quyền lực nhu ếch ngồi đáy giếng. Tôi phải lấp đầy hố sâu ngăn cách đó bằng kiến thức và kinh nghiệm tù doanh nghiệp của tôi”" (tr. 37).

Từ sự tích hợp Đông - Tây, truyền thống hiện đại, hệ giá trị Lee Muyng Bak có những đóng góp riêng và mới mẻ cho hệ giá trị chung của văn hóa Hàn Quốc.

Theo Hofstede, trong 6 chiều kích nói trên, ảnh hưởng trực tiếp và mạnh mẽ đối với mô hình tổ chức doanh nghiệp là sự tương tác giữa 2 chiều kích (1) - Khoảng cách quyền lực và (4) - Tâm lý tránh sự bất định. Từ đó, có thể nhận diện 4 mô hình tổ chức doanh nghiệp khác nhau:

(I) Mô hình Kim tư tháp: Doanh nghiệp có khoảng cách quyền lực lớn, tránh bất định cao.

(II) Mô hình Cỗ máy: Doanh nghiệp có khoảng cách quyền lực nhỏ, tránh bất định cao.

(III) Mô hình Thị truờng: Doanh nghiệp có khoảng cách quyền lực nhỏ, tránh bất định thấp.
(IV) Mô hình Gia đình: Doanh nghiệp có khoảng cách quyền lực lớn, tránh bất định thấp.

Trong khi hệ giá trị chung Hàn Quốc (qua khảo sát của Hofstede) cho thấy mô hình (I) - Doanh nghiệp Kim tự tháp thì hệ giá trị Lee Myung Bak lại thuộc mô hình (III) - Doanh nghiệp Thị trường, cùng loại với mô hình Hoa Kỳ.

\section{Kết luận}

Qua một nhân vật xuất chúng mà số phận gắn bó với sự hình thành, phát triển một trong những tập đoàn hàng đầu của Hàn Quốc, Không có thần thoại giúp chúng ta cảm hiểu nguồn sức mạnh đã làm nên "kỳ tích sông Hàn" (Han River Miracle), tính cách con người và bản sắc dân tộc Hàn nói chung; đặc điểm văn hóa doanh nhân, văn hóa doanh nghiệp Hàn Quốc nói riêng. Lee Myung Bak kết tinh những giá trị Hàn Quốc, rất truyền thống Á Đông, đồng thời tiếp biến những giá trị tiên tiến tinh hoa rất hiện đại của phương Tây.

Hồi ký Không có thần thoại được xuất bản lần đầu ở Hàn Quốc năm 1995. Lee Myung Bak cùng với những "người hùng" khác của các tập đoàn lớn, trở thành những thần tượng doanh nhân, những thần tượng kinh doanh báo quốc mà không chỉ giới trẻ mà đông đảo người Hàn ngưỡng mộ. Như mặt trời trên những đỉnh non cao tỏa ánh sáng ngập tràn thung lũng, những biểu tượng Lee Myung Bak có thể truyền cảm hứng, lôi cuốn tâm thức cả một dân tộc.

Đối với người Việt Nam mà khá đông đang bị cuốn hút bởi ảnh hưởng văn hóa đại chúng Hàn Quốc qua phim truyền hình, nhạc pop, mỹ phẩm, thời trang... với các thần tượng của showbiz (celebrities) thì Không có thần thoại và các truyện ký về "người hùng" của các tập đoàn lớn đã mang đến một say mê mới, một dạng thức khác của văn hóa thần tượng. Tìm đọc các truyện ký này không chỉ có những người trẻ tuổi mà còn có đông đảo độc giả mong muốn khám phá bí quyết của 
"kỳ tích sông Hàn", mong muốn hiểu biết những giá trị có tính nhân loại của Hàn Quốc, mong muốn học hỏi kinh nghiệm Hàn Quốc cho phát triển Việt Nam. Nếu quả thật như ý kiến của một số học giả rằng người Việt nói chung, sinh viên Việt nói riêng còn thiếu "chí nghiệp chủ” thì có thể nói, những cuốn sách doanh nhân thành đạt trên thế giới, trong đó có Hàn Quốc đã góp phần khơi gợi ý chí ấy.

\section{Tài liệu tham khảo}

\section{Tiếng Việt}

Geert Hofstede, Gert Jan Hofstede, Michael Minkov (2013). Văn hóa và tổ chức - Phần mềm tu duy. Giao luu giũa các nền văn hóa và tầm quan trọng của nó cho sư sống còn (Đinh Việt Hòa và Pailema dịch). Hà Nội: NXB Đại học Quốc gia Hà Nội.

Phan Thị Thu Hiền (2015). Tiếp cận văn hóa so sánh và văn hóa đại chúng trong nghiên cứu hệ giá trị (trường hợp văn hóa Hàn Quốc). Trong Trần Ngọc
Thêm (cb) Một số vấn đề về hệ giá trị Việt Nam trong giai đoạn hiện tại. Tp. Hồ Chí Minh: NXB Đại học Quốc gia Tp. Hồ Chí Minh.

Lee Myung Bak (2009). Không có thần thoại (Cho Jae Hyun dịch). Hội Hữu nghị Hàn-Việt, Seoul.

Trần Ngọc Thêm (2013). Nhũng vấn đề văn hóa học lý luận và úng dụng [Chương Ba, III. "Vai trò của tính cách dân tộc trong tiến trình phát triển ở Hàn Quốc (so sánh với Việt Nam)"; IV. "Vai trò của chủ nghĩa gia đình ở Korea: từ truyền thống đến hiện đại”]. Tp. Hồ Chí Minh: Nxb Văn hóa Văn nghệ Tp Hồ Chí Minh.

\section{Tiếng Anh}

Chan Sup Chang \& Nahn Joo Chang (1994). The Korean Management System. Cultural, Political, Economic Foundations. Quorum Books - Westport, Connecticut, London.

Geert Hofstede (2011). Dimensionalizing Cultures: The Hofstede Model in Context. International Association of Cross-Cultural Psychology.

\title{
HOFSTEDE'S DIMENSIONS IN KOREAN CORPORATE CULTURE THROUGH THE AUTOBIOGRAPHY THERE IS NO LEGEND BY LEE MYUNG BAK
}

\author{
Phan Thi Thu Hien \\ University of Social Sciences and Humanities, Vietnam National University Ho Chi Minh City, \\ 10-12 Dinh Tien Hoang, Ben Nghe Ward, District 1, Ho Chi Minh City, Vietnam
}

\begin{abstract}
The autobiography There is no legend by Mr. Lee Myung Bak, the former Chairman of Hyundai and the former President of the Republic of Korea, is a representative and typical case of narrative works on the lives of the "Heroes" of Korean chaebols (groups). Through the life of an eminent figure whose fate is attached to the formation and development of one of Korea's leading corporations, the work There is no legend helps us understand the power that has made "the Miracle of the Han River" [the rapid economic growth in South Korea in the later half of the $20^{\text {th }}$ century during which South Korea transformed from a developing country to a developed country] as well as the Korean national identity in general and the characteristics of Korean corporate culture in particular. Using Geert Hostede's theory frame of 6 corporate culture dimensions, this paper analyzes Lee Myung Bak's autobiography from interdisciplinary approach to make clear some characteristics of Korean corporate culture in modern times.
\end{abstract}

Keywords: Korean popular literature, Korean corporate culture, Hofstede culture dimensions, Hyundai chaebol (Hyundai group), the autobiography There is no legend by Lee Myung Bak 